\section{Measurement and Correlation of Phase Diagram Data of Hydrophilic Alcohols (1-Propanol/2-Propanol) + + Salts $\left(\mathrm{Na}_{2} \mathrm{SO}_{4} /\left(\mathrm{NH}_{4}\right)_{2} \mathrm{SO}_{4} / \mathrm{NH}_{4} \mathrm{NO}_{3}\right)+$ Water Systems}

\author{
G. Khayati" and M. Shahriari \\ Department of Chemical Engineering, Faculty of Engineering, \\ University of Guilan, Rasht, P. O. Box 41635-3756, Iran
}

doi: 10.15255/CABEQ.2015.2308

Original scientific paper Received: September 24, 2015 Accepted: February 29, 2016

Binodal data and the ternary liquid-liquid equilibria (LLE) was experimentally determined at $298.15 \mathrm{~K}$ for hydrophilic alcohols (1-propanol or 2-propanol) + salts $\left(\mathrm{Na}_{2} \mathrm{SO}_{4}\right.$, $\left(\mathrm{NH}_{4}\right)_{2} \mathrm{SO}_{4}$ or $\left.\mathrm{NH}_{4} \mathrm{NO}_{3}\right)+$ water systems. The salting-out and the phase-forming abilities of the salts and alcohols for the investigated ATPSs were discussed. The salting-out abilities of the investigated salts follow the order $\mathrm{Na}_{2} \mathrm{SO}_{4}>\left(\mathrm{NH}_{4}\right)_{2} \mathrm{SO}_{4}>\mathrm{NH}_{4} \mathrm{NO}_{3}$, which can be indicated by the location of the binodal curves plotted in mass fraction, the effective excluded volume (EEV), the salting-out coefficient $(K)$, the size of the ions, and the Gibbs free energy of hydration of the ions. The phase-separation ability of the studied hydrophilic alcohols was discussed on the basis of the dielectric constant and boiling point of the alcohols. The results show that the phase-separation capability of the system consists of different hydrophilic alcohols in the order: 1-propanol>2-propanol. Furthermore, the binodal curves of the studied systems were satisfactorily correlated by a nonlinear equation with four parameters. The reliability of the calculation method and the corresponding LLE data was successfully proved by the Othmer-Tobias equation and the Bancroft equation.

Key words:

liquid-liquid equilibrium, aqueous two-phase system, hydrophilic alcohols, salting-out effect, phase-forming ability

\section{Introduction}

Aqueous two-phase systems (ATPSs) are composed of two immiscible aqueous phases that are in equilibrium. As one of the separation methods, aqueous two-phase extraction (ATPE) has advantages of biocompatibility, process integration capability, and large-scale feasibility ${ }^{1}$. As far as we know, ATPE has been used for the separation of proteins $^{2}$, enzymes ${ }^{3-4}$, organic $\operatorname{acids}^{5-6}$, and so on. Based on the composition of ATPS, they can be classified into the following categories: polymer-based ATPS, ionic liquid (IL)-based ATPS, surfactant-based ATPS, and hydrophilic alcohols-based ATPS. Among the ATPS mentioned above, the weaknesses of the polymer-based ATPS are high price and high viscosity. The ionic liquid (IL)-based ATPS also shares the disadvantage of high cost. In comparison with other ATPSs, the hydrophilic alcohol-based have advantages of low viscosity and low cost simultaneously ${ }^{7}$. And they have the potential to achieve the desired purification and concentration

"Corresponding author: e-mail: khayati@guilan.ac.ir; tel.: +98 9111329514 of the product in a single step ${ }^{8}$. In addition, the hydrophilic alcohol can be recycled and reused in some way ${ }^{7}$, which will further cut the process costs.

Based on our knowledge, there are only two works in the literature describing phase diagrams of ternary systems composed by 2-propanol $+\left(\mathrm{NH}_{4}\right)_{2} \mathrm{SO}_{4}+$ $+\mathrm{H}_{2} \mathrm{O}^{9}$ and 2-propanol $+\mathrm{Na}_{2} \mathrm{SO}_{4} /\left(\mathrm{NH}_{4}\right)_{2} \mathrm{SO}_{4}+\mathrm{H}_{2} \mathrm{O}^{40}$. None of these reports have conducted a systematic study on the phase-formation ability of the sulfate salts in hydrophilic alcohol + salt + water systems. Also, no LLE data have been previously reported in the literature for the 1-propanol $+\mathrm{Na}_{2} \mathrm{SO}_{4} /\left(\mathrm{NH}_{4}\right)_{2} \mathrm{SO}_{4}$ + water systems, and aliphatic alcohols $+\mathrm{NH}_{4} \mathrm{NO}_{3}$ + water systems. Therefore, the aim of this work is to systematically investigate the liquid-liquid equilibria for ternary systems of [hydrophilic alcohols (1-propanol/2-propanol)+salts $\left(\mathrm{Na}_{2} \mathrm{SO}_{4} /\left(\mathrm{NH}_{4}\right)_{2} \mathrm{SO}_{4} /\right.$ $\mathrm{NH}_{4} \mathrm{NO}_{3}$ ) +water]. The salting-out ability of the salts and the phase-forming ability of the hydrophilic alcohols were discussed by the effective excluded volume $(\mathrm{EEV})$ and salting-out coefficient $\left(K_{\mathrm{s}}\right)$ of the mentioned salts. Furthermore, the dependability of the calculation method was tested by the Othmer-Tobias and Bancroft equations. 


\section{Materials and methods}

\section{Materials}

The chemicals 1-propanol, 2-propanol, $\mathrm{Na}_{2} \mathrm{SO}_{4}$, $\left(\mathrm{NH}_{4}\right)_{2} \mathrm{SO}_{4}$ and $\mathrm{NH}_{4} \mathrm{NO}_{3}$ were supplied from Merck with a minimum purity of $99.5 \%, 99.8 \%, 98.5 \%$, $99.5 \%$, and $95.0 \%$, respectively. The salts were dried in an oven at about $393.15 \mathrm{~K}$ for $24 \mathrm{~h}$ before use. All chemicals were used without further purification. Double distilled deionized water was used in all experiments.

\section{Apparatus and procedure}

The experimental apparatus employed is similar to the one used previously ${ }^{11}$. A glass vessel with $50 \mathrm{~cm}^{3}$ volume was used to carry out the experiments. It was provided with an external jacket in which water was circulated from a controlled thermostat at constant temperature (with a precision of $\pm 0.1 \mathrm{~K}$ ), and a magnetic stirrer was used to agitate the liquid mixture in the cell. The cloud point titration method was performed to collect the binodal curve data. In this method, the salt solution of known concentration was titrated with 1-propanol/2-propanol or vice versa, until the clear solution turned turbid. Water was then added to the mixture to make it clear again. The procedure was repeated to obtein more cloud points, and compositions for each point were determined by using an analytical balance with an uncertainty of $\pm 0.0001 \mathrm{~g}$.

The phase equilibrium experiments were carried out to determine the tie-lines. The feed samples were prepared by mixing an appropriate mass of alcohols (2-propanol/1-propanol), salts $\left(\mathrm{Na}_{2} \mathrm{SO}_{4} /\right.$ $\left.\left(\mathrm{NH}_{4}\right)_{2} \mathrm{SO}_{4} / \mathrm{NH}_{4} \mathrm{NO}_{3}\right)$ and water in a vessel, and the mass of each composition was determined by the same analytical balance mentioned above. After two hours of mixing, equilibrium was achieved by letting the mixture rest for more than $10 \mathrm{~h}$ at the desired temperature $(298.15 \mathrm{~K})$ until it was separated into two clear phases. After phase separation, the top phase was carefully withdrawn and the mass measured by the analytical balance, while the mass of the bottom phase was determined by mass balance equation. Also, the densities of both phases were determined using measurements of weight and volume.

The salt concentration in each phase was determined gravimetrically by transferring a liquid sample to a watch glass, and evaporating the solution at $403.15 \mathrm{~K}$ until a constant mass was achieved. The mass fractions of alcohols were analyzed using a Konik gas chromatography (GC) system equipped with a thermal conductivity detector (TCD) and Shimadzu C-R2AX integrator. The GC oven temperature was held at $40{ }^{\circ} \mathrm{C}$ for 5 minutes and then programmed to attain a temperature of $270{ }^{\circ} \mathrm{C}$ at $10{ }^{\circ} \mathrm{C} \mathrm{min}-1$. The injector temperature was $280{ }^{\circ} \mathrm{C}$ with a split ratio 20:1. Helium was used as a carrier gas with a constant flow rate of $1.3 \mathrm{~mL} \mathrm{~min}{ }^{-1}$. The measurements were repeated at least three times.

The tie-line length (TLL) and the slope (S) of the tie-line at different compositions were also calculated by using the following two equations respectively:

$$
\begin{gathered}
\text { TLL }=\sqrt{\left(w_{1}^{t}-w_{1}^{b}\right)^{2}+\left(w_{2}^{t}-w_{2}^{b}\right)^{2}} \\
S=\frac{w_{1}^{t}-w_{1}^{b}}{w_{2}^{t}-w_{2}^{b}}
\end{gathered}
$$

where $w_{1}{ }^{\mathrm{t}}$ and $w_{2}{ }^{\mathrm{t}}$ represent the equilibrium compositions (in mass fraction) of hydrophilic alcohol (1) and salt (2) in the top phase, respectively, $w_{1}{ }^{\mathrm{b}}$ and $w_{2}{ }^{\mathrm{b}}$ represent the equilibrium compositions (in mass fraction) of hydrophilic alcohol (1) and salt (2) in bottom phase, respectively.

\section{Results and discussion}

Liquid-liquid equilibria (LLE) are the key in improving the performance of an extraction process and understanding the phase behavior of systems exhibiting two liquid phases ${ }^{12}$. Only a few reports found in the literature focus on the study of ternary systems composed by 2-propanol $+\mathrm{Na}_{2} \mathrm{SO}_{4} /$ $\left(\mathrm{NH}_{4}\right)_{2} \mathrm{SO}_{4}+\mathrm{H}_{2} \mathrm{O}$ systems $^{9-10}$. Fig. 1B compares the binodal curves obtained in this work for 2-propanol $+\mathrm{Na}_{2} \mathrm{SO}_{4} /\left(\mathrm{NH}_{4}\right)_{2} \mathrm{SO}_{4}+\mathrm{H}_{2} \mathrm{O}$ systems with those obtained from literature data. According to this figure, our measurements agree with literature values. Also, scattering of the new experimental data was less than $5 \%$, which can be related to experimental uncertainties. Therefore, we systematically studied the liquid-liquid phase equilibrium and binodal data for the ternary hydrophilic alcohols (2-propanol/1-propanol) + salts $\left(\mathrm{Na}_{2} \mathrm{SO}_{4} /\left(\mathrm{NH}_{4}\right)_{2} \mathrm{SO}_{4} / \mathrm{NH}_{4} \mathrm{NO}_{3}\right)$ +water systems. The results are shown in Table 1. Also, the tie-line lengths (TLL) and slopes (S) for ternary systems are shown in Table 2 as mass fractions at $298.15 \mathrm{~K}$, and the tie-lines at $298.15 \mathrm{~K}$ are drawn in Fig. 2. It can be observed that, when the salts concentration are constant (in 1-propanol $+\mathrm{NH}_{4} \mathrm{NO}_{3}+$ $\mathrm{H}_{2} \mathrm{O}$ and 2-propanol $+\left(\mathrm{NH}_{4}\right)_{2} \mathrm{SO}_{4}+\mathrm{H}_{2} \mathrm{O}$ systems), the increase in the amount of hydrophilic alcohols leads to the increase in the tie-line length. Also, increasing both the amounts of hydrophilic alcohols and the salts (in 1-propanol $+\left(\mathrm{NH}_{4}\right)_{2} \mathrm{SO}_{4}+\mathrm{H}_{2} \mathrm{O}$ ) can result in the increase in the tie-line length (Table 2 and Fig. 2). The results show that increasing the tie-line can promote phase-separation. Therefore, in studying the phase-separation of hydrophilic alcohol-salt ATPS, we should increase the 
Table 1 -Binodal data for the hydrophilic alcohols (1-propanol/2-propanol) (1) + salts ( $\mathrm{Na}_{2} \mathrm{SO}_{4},(\mathrm{NH})_{2} \mathrm{SO}_{4}$ $\mathrm{NH}_{4} \mathrm{NO}_{3}$ ) (2) $+\mathrm{H}_{2} \mathrm{O}(3)$ systems at $\mathrm{T}=298.15 \mathrm{~K}$

\begin{tabular}{|c|c|c|c|c|c|c|c|}
\hline $100 w_{1}$ & $100 w_{2}$ & $100 w_{1}$ & $100 w_{2}$ & $100 w_{1}$ & $100 w_{2}$ & $100 w_{1}$ & $100 w_{2}$ \\
\hline \multicolumn{8}{|c|}{ 1-propanol $+\mathrm{Na}_{2} \mathrm{SO}_{4}$} \\
\hline 3.77 & 19.24 & 6.00 & 14.56 & 9.69 & 10.51 & 14.38 & 7.70 \\
\hline 3.96 & 18.72 & 6.71 & 13.99 & 9.73 & 10.20 & 15.40 & 7.20 \\
\hline 4.84 & 17.39 & 7.10 & 13.46 & 10.66 & 9.83 & 16.28 & 6.65 \\
\hline 5.56 & 16.53 & 7.72 & 12.92 & 11.54 & 9.28 & 21.96 & 5.24 \\
\hline 5.44 & 16.07 & 7.81 & 12.44 & 12.79 & 8.72 & & \\
\hline 5.35 & 15.61 & 8.77 & 11.86 & 12.99 & 8.26 & & \\
\hline \multicolumn{8}{|c|}{ 1-propanol $+\mathrm{NH}_{4} \mathrm{NO}_{3}$} \\
\hline 5.10 & 56.94 & 6.55 & 49.52 & 9.18 & 43.59 & 12.91 & 37.45 \\
\hline 5.48 & 53.87 & 7.20 & 48.25 & 9.89 & 42.35 & 14.03 & 36.10 \\
\hline 5.82 & 52.73 & 7.37 & 47.24 & 9.80 & 41.49 & 16.76 & 33.80 \\
\hline 6.34 & 51.51 & 8.24 & 45.88 & 11.05 & 40.00 & 20.69 & 29.40 \\
\hline 6.13 & 50.69 & 8.85 & 44.66 & 12.08 & 38.68 & & \\
\hline \multicolumn{8}{|c|}{ 1-propanol $+\left(\mathrm{NH}_{4}\right)_{2} \mathrm{SO}_{4}$} \\
\hline 5.96 & 18.53 & 7.69 & 15.69 & 11.94 & 11.00 & 18.73 & 7.31 \\
\hline 5.53 & 19.22 & 8.21 & 15.14 & 12.83 & 10.46 & 20.88 & 6.72 \\
\hline 5.79 & 18.84 & 8.43 & 14.65 & 12.72 & 10.03 & 22.43 & 6.20 \\
\hline 6.27 & 18.27 & 9.90 & 13.51 & 14.17 & 9.44 & 27.45 & 5.36 \\
\hline 6.78 & 17.24 & 10.10 & 13.03 & 14.22 & 9.00 & 32.45 & 4.22 \\
\hline 7.24 & 16.69 & 10.24 & 12.57 & 15.55 & 8.44 & & \\
\hline 7.30 & 16.22 & 11.10 & 11.55 & 16.88 & 7.89 & & \\
\hline
\end{tabular}

$$
\text { 2-propanol }+\mathrm{Na}_{2} \mathrm{SO}_{4}
$$

\begin{tabular}{rrrrrrrr}
29.77 & 6.10 & 18.80 & 9.50 & 10.90 & 15.30 & 7.98 & 19.80 \\
27.21 & 6.50 & 17.30 & 9.90 & 10.40 & 16.30 & 6.61 & 22.00 \\
25.70 & 6.80 & 14.87 & 11.40 & 9.97 & 16.90 & 6.18 & 22.70 \\
23.80 & 7.20 & 13.10 & 13.20 & 9.40 & 17.90 & 5.66 & 24.50 \\
21.10 & 8.10 & 12.03 & 13.45 & 8.98 & 18.39 & 5.02 & 28.20 \\
19.60 & 8.80 & 11.58 & 14.21 & 8.50 & 19.05 & & \\
\hline \multicolumn{7}{c}{2 -propanol $+\mathrm{NH}_{4} \mathrm{NO}_{3}$} \\
50.31 & 21.37 & 19.85 & 40.08 & 10.42 & 50.15 & 7.00 & 58.60 \\
43.47 & 24.88 & 18.12 & 41.78 & 10.10 & 51.24 & 5.56 & 60.45 \\
40.18 & 27.09 & 16.38 & 43.49 & 8.84 & 52.86 & 5.88 & 61.18 \\
36.10 & 29.63 & 14.92 & 45.08 & 7.37 & 55.58 & & \\
29.29 & 33.94 & 13.10 & 46.93 & 7.74 & 56.29 & & \\
25.86 & 36.34 & 11.19 & 48.84 & 6.82 & 57.77 & & \\
\hline \multicolumn{7}{c}{$2-$ propanol $+\left(\mathrm{NH}_{4}\right)_{2} \mathrm{SO}_{4}$} \\
9.62 & 19.78 & 14.92 & 15.67 & 22.46 & 10.47 & 36.84 & 5.68 \\
10.54 & 19.23 & 15.11 & 15.28 & 23.89 & 9.89 & 41.21 & 5.12 \\
10.84 & 18.72 & 15.67 & 14.76 & 26.10 & 8.50 & 45.60 & 4.48 \\
10.44 & 18.36 & 16.67 & 14.17 & 30.68 & 7.59 & 50.67 & 3.89 \\
13.06 & 17.28 & 19.81 & 12.03 & 33.08 & 7.03 & & \\
13.01 & 16.88 & 21.14 & 11.43 & 34.13 & 6.59 & & \\
13.95 & 16.35 & 22.28 & 10.88 & 37.45 & 5.94 & & \\
\hline
\end{tabular}

$w_{1}$, mass fractions of hydrophilic alcohol $w_{2}$, mass fractions of salt
Table 2 - Tie-line data for the hydrophilic alcohol (1) + salt (2) $+\mathrm{H}_{2} \mathrm{O}$ (3) systems at $\mathrm{T}=298.15 \mathrm{~K}$

\begin{tabular}{|c|c|c|c|c|c|c|c|}
\hline \multicolumn{8}{|c|}{ ATPS } \\
\hline \multicolumn{2}{|c|}{$\begin{array}{c}\text { Total } \\
\text { compositions }\end{array}$} & \multicolumn{2}{|c|}{ Organic phase } & \multicolumn{2}{|c|}{ Aqueous phase } & \multirow{2}{*}{ TLL } & \multirow{2}{*}{$\mathrm{S}$} \\
\hline $100 w_{1}$ & $100 w_{2}$ & $100 w_{1}$ & $100 w_{2}$ & $100 w_{1}$ & $100 w_{2}$ & & \\
\hline \multicolumn{8}{|c|}{ 1-propanol $+\mathrm{Na}_{2} \mathrm{SO}_{4}$} \\
\hline 11.92 & 12.44 & 55.42 & 2.20 & 6.45 & 13.79 & 0.49 & -4.18 \\
\hline 14.00 & 10.50 & 49.81 & 2.31 & 8.31 & 11.99 & 0.42 & -4.30 \\
\hline 17.97 & 12.44 & 63.55 & 1.81 & 4.92 & 15.45 & 0.60 & -4.29 \\
\hline 24.00 & 12.46 & 68.09 & 1.77 & 4.62 & 17.35 & 0.65 & -4.06 \\
\hline \multicolumn{8}{|c|}{ 1-propanol $+\mathrm{NH}_{4} \mathrm{NO}_{3}$} \\
\hline 13.96 & 44.84 & 57.05 & 13.72 & 7.14 & 49.49 & 0.61 & -1.40 \\
\hline 18.16 & 44.77 & 73.86 & 8.31 & 6.65 & 52.58 & 0.80 & -1.51 \\
\hline 22.04 & 44.96 & 80.25 & 7.53 & 4.86 & 56.31 & 0.89 & -1.54 \\
\hline 26.01 & 44.84 & 83.75 & 7.02 & 4.35 & 59.07 & 0.94 & -1.52 \\
\hline \multicolumn{8}{|c|}{ 1-propanol $+\left(\mathrm{NH}_{4}\right)_{2} \mathrm{SO}_{4}$} \\
\hline 16.15 & 10.98 & 50.63 & 2.95 & 10.99 & 12.23 & 0.40 & -4.27 \\
\hline 23.97 & 10.97 & 67.22 & 1.58 & 9.13 & 14.49 & 0.59 & -4.49 \\
\hline 32.06 & 10.98 & 73.61 & 1.17 & 6.51 & 17.10 & 0.68 & -4.23 \\
\hline 40.00 & 11.00 & 81.96 & 1.07 & 6.06 & 18.99 & 0.78 & -4.21 \\
\hline \multicolumn{8}{|c|}{ 2-propanol $+\mathrm{Na}_{2} \mathrm{SO}_{4}$} \\
\hline 17.07 & 12.15 & 37.05 & 5.31 & 12.49 & 13.55 & 0.25 & -2.97 \\
\hline 20.04 & 12.02 & 40.89 & 5.10 & 11.78 & 15.24 & 0.30 & -2.87 \\
\hline 24.00 & 12.02 & 44.02 & 4.99 & 9.11 & 17.33 & 0.37 & -2.82 \\
\hline 28.01 & 11.88 & 49.59 & 4.69 & 8.01 & 19.09 & 0.44 & -2.88 \\
\hline \multicolumn{8}{|c|}{ 2-propanol $+\mathrm{NH}_{4} \mathrm{NO}_{3}$} \\
\hline 13.85 & 49.88 & 53.04 & 20.54 & 7.13 & 55.07 & 0.57 & -1.33 \\
\hline 15.97 & 49.96 & 56.51 & 19.08 & 7.15 & 57.06 & 0.62 & -1.30 \\
\hline 18.00 & 50.00 & 59.09 & 18.03 & 6.64 & 59.10 & 0.66 & -1.27 \\
\hline 19.81 & 49.93 & 61.50 & 17.04 & 5.21 & 61.50 & 0.71 & -1.26 \\
\hline \multicolumn{8}{|c|}{ 2-propanol $+\left(\mathrm{NH}_{4}\right)_{2} \mathrm{SO}_{4}$} \\
\hline 23.00 & 12.00 & 41.75 & 5.03 & 15.89 & 14.64 & 0.27 & -2.69 \\
\hline 26.04 & 12.00 & 46.44 & 4.37 & 13.06 & 16.83 & 0.35 & -.2 .67 \\
\hline 30.00 & 12.00 & 52.01 & 3.75 & 10.15 & 19.44 & 0.44 & -2.66 \\
\hline 34.00 & 12.00 & 58.22 & 3.22 & 8.34 & 21.31 & 0.53 & -2.75 \\
\hline
\end{tabular}

$w_{1}$, mass fractions of hydrophilic alcohol

$w_{2}$, mass fractions of salt

amount of alcohol and salt. Such results were reported by Han et al. ${ }^{7}$ for hydrophilic alcohol + sodium hydroxide + water systems.

\section{Effect of different salts on the phase formation}

The salting-out effect in ATPS is noteworthy for industrial applications relevant to separation technologies. In aqueous two-phase systems, the salt type is an important factor, while the salting-out effect is the driving force for the formation of ATPS. The conditions of LLE and the distribution of com- 
ponents in the ATPS are usually under the influence of the electrolytes present ${ }^{13}$. In order to better study the phase-separation abilities of salts, the binodal curves of alcohols-salts ATPSs at $298.15 \mathrm{~K}$ are shown in Fig. 1. It can be seen from Fig. 1 that the two-phase area of alcohols $+\mathrm{Na}_{2} \mathrm{SO}_{4}$ systems is larger than that of alcohols $+\left(\mathrm{NH}_{4}\right)_{2} \mathrm{SO}_{4}$ systems. Also, the two-phase area of alcohols $+\left(\mathrm{NH}_{4}\right)_{2} \mathrm{SO}_{4}$ systems is larger than that of alcohols $+\mathrm{NH}_{4} \mathrm{NO}_{3}$ systems. In other words, the phase-forming ability of the investigated salts follows the order: $\mathrm{Na}_{2} \mathrm{SO}_{4}>$ $\left(\mathrm{NH}_{4}\right)_{2} \mathrm{SO}_{4}>\mathrm{NH}_{4} \mathrm{NO}_{3}$. This is mainly due to the higher salting-out effect of the $\mathrm{Na}_{2} \mathrm{SO}_{4}$ salt. The $\mathrm{Na}_{2} \mathrm{SO}_{4}$ salt has higher salting-out effect than the $\left(\mathrm{NH}_{4}\right)_{2} \mathrm{SO}_{4}$, and the $\left(\mathrm{NH}_{4}\right)_{2} \mathrm{SO}_{4}$ has higher salting-out effect than the $\mathrm{NH}_{4} \mathrm{NO}_{3}$ salt. The salting-out ability of a cation or anion is related to its ionic charge and hydration radius ${ }^{6}$. The strength of ion solvation mainly depends on electrostatic attraction. Since two the salts, $\mathrm{Na}_{2} \mathrm{SO}_{4}$ and $\left(\mathrm{NH}_{4}\right)_{2} \mathrm{SO}_{4}$, have the same anion, the different cations have an im-
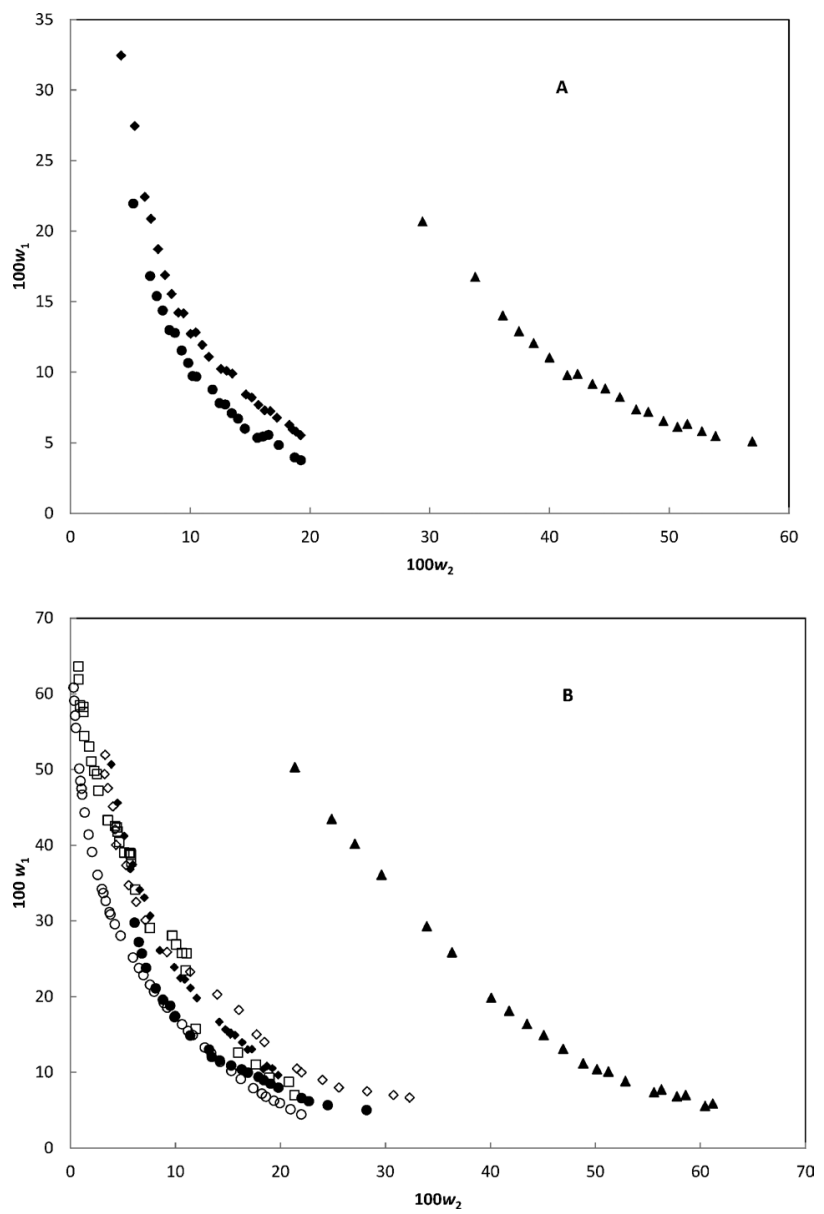

Fig. 1 - Effect of salt type on the binodal curves in mass fraction for hydrophilic alcohols(1)+salts(2)+water(3) systems at $298.15 \mathrm{~K}$ : (A) 1-propanol and (B) 2-propanol; (Bold symbols) this work [alcohols + salts ( $\mathbf{\Delta} \mathrm{NH}_{4} \mathrm{NO}_{3}, \circ\left(\mathrm{NH}_{4}\right)_{2} \mathrm{SO}_{4}$, - $\left.\mathrm{Na} \mathrm{SO}_{2}\right)+\mathrm{H}_{2} \mathrm{O}$ ] and (open symbols) literature data [alcohols + salt $\left.\left(\diamond\left(\mathrm{NH}_{4}\right)_{2} \mathrm{SO}_{4}\right)+\mathrm{H}_{2} \mathrm{O}\right]^{9}$ [alcohols + salts $\left(\bullet\left(\mathrm{NH}_{4}\right)_{2} \mathrm{SO}_{4}\right.$ $\left.\left.\circ \mathrm{Na}_{2} \mathrm{SO}_{4}\right)+\mathrm{H}_{2} \mathrm{O}\right]^{10}$. portant influence on their electrostatic attractions. Sodium and ammonium ions have radii of 102 and $148 \mathrm{pm}$, respectively. It can be seen that the salting-out effect increases as the size of the cation decreases. It seems that in these systems, the size of the cation may be responsible for this trend. Similar results were observed by Chen et al. ${ }^{14}$ They showed that, in water + 1-propanol systems, the two-phase region with a certain composition of $\mathrm{KCl}$ is larger than the one with identical composition of $\mathrm{NH}_{4} \mathrm{Cl}$. The salting-out ability can also be related to the Gibbs free energy of hydration of ions $\left(\Delta G_{h y d}\right)$, as proposed by Marcus ${ }^{15}$. It was found that better salting-out is observed when the ions have a more negative Gibbs free energy. The Gibbs free energies of hydration for sodium and ammonium ions are -365 and $-285 \mathrm{~kJ} \mathrm{~mol}^{-1}$ respectively, which also certify the conclusion that the salting-out ability of $\mathrm{Na}_{2} \mathrm{SO}_{4}$ is stronger than that of $\left(\mathrm{NH}_{4}\right)_{2} \mathrm{SO}_{4}$. The more negative is the $\Delta G_{h y d}$ value of an ion, the greater is the salting out ability. This behavior can be explained by comparing the $\Delta G_{h v d}$ values for the anions sulfate and nitrate $\left(-1080\right.$ and $-300 \mathrm{~kJ} \mathrm{~mol}^{-1}$ respectively), it can be concluded that the salting-out ability of $\left(\mathrm{NH}_{4}\right)_{2} \mathrm{SO}_{4}$ is stronger than $\mathrm{NH}_{4} \mathrm{NO}_{3}$ (the two salts have the same cation). Furthermore, cations with a higher valence are better salting-out agents than cations with a lower-valence, because higher-valence cations are hydrated by more water than lower valence cations, thus decreasing the amount of water available to hydrate alcohols.

Furthermore, we calculated the effective excluded volume (EEV) and the salting-out coefficient $\left(K_{\mathrm{s}}\right)$ to evaluate the salting-out ability of $\mathrm{Na}_{2} \mathrm{SO}_{4},\left(\mathrm{NH}_{4}\right)_{2} \mathrm{SO}_{4}$ and $\mathrm{NH}_{4} \mathrm{NO}_{3}$ in alcohol+water systems.

In this work, the EEV theory ${ }^{1}$ proposed by Guan et al. ${ }^{16}$ was used to correlate binodal data and calculate the effective excluded volume of salts. The EEV of $\mathrm{Na}_{2} \mathrm{SO}_{4},\left(\mathrm{NH}_{4}\right)_{2} \mathrm{SO}_{4}$ and $\mathrm{NH}_{4} \mathrm{NO}_{3}$ in different hydrophilic alcohol-water component solvents was calculated by the following equation:

$$
\ln \left(V_{213}^{*} \frac{w_{2}}{M_{2}}+f_{213}\right)+\left(V_{213}^{*} \frac{w_{1}}{M_{1}}\right)=0
$$

where $V^{*}{ }_{213}$ and $f_{213}$ state the scaled EEV of the salt and the effective volume fraction of the salt in the network structure of hydrophilic alcohol, respectively. $M$ and $w$ represent the molecular mass and the mass fraction, subscripts " 1 " and " 2 " show the hydrophilic alcohol and salt, respectively. Values of $V_{213}^{*}$ and $f_{213}$ obtained from the correlation of exper-

\footnotetext{
${ }^{1}$ This theory is based on the statistical geometry methods developed, and states that any molecule species in a solution is distributed at random and every system composition on the solubility curve is a geometrically saturated solution of one solute in the presence of another.
} 
Table 3 -Values of parameters of Eq. (3) for the studied ATPS at temperature $T=298.15 \mathrm{~K}$

\begin{tabular}{c|c|c|c|c}
\hline ATPS & $\begin{array}{c}V^{*}{ }_{213} \\
\mathrm{~g} \mathrm{~mol}^{-1}\end{array}$ & $f_{213}$ & $R^{2}$ & $\begin{array}{c}100 \\
s d^{\mathrm{a}}\end{array}$ \\
\hline 1-propanol $+\mathrm{Na}_{2} \mathrm{SO}_{4}+\mathrm{H}_{2} \mathrm{O}$ & 632.8 & -0.1281 & 0.9897 & 0.77 \\
1-propanol $+\mathrm{NH}_{4} \mathrm{NO}_{3}+\mathrm{H}_{2} \mathrm{O}$ & 217.8 & -0.4496 & 0.9779 & 4.86 \\
1-propanol $+\left(\mathrm{NH}_{4}\right)_{2} \mathrm{SO}_{4}+\mathrm{H}_{2} \mathrm{O}$ & 538.4 & -0.1192 & 0.9873 & 1.27 \\
2-propanol $+\mathrm{Na}_{2} \mathrm{SO}_{4}+\mathrm{H}_{2} \mathrm{O}$ & 460.9 & -0.0833 & 0.9789 & 1.74 \\
2-propanol $+\mathrm{NH}_{4} \mathrm{NO}_{3}+\mathrm{H}_{2} \mathrm{O}$ & 115.1 & 0.0792 & 0.9840 & 2.80 \\
2-propanol $+\left(\mathrm{NH}_{4}\right)_{2} \mathrm{SO}_{4}+\mathrm{H}_{2} \mathrm{O}$ & 389.9 & -0.7962 & 0.9965 & 1.15 \\
\hline & ${ }^{n} s d=\left(\sum_{i=1}^{n}\left(\mathrm{w}_{1}^{c a l}-w_{1}^{\text {exp }}\right)^{2} / n\right)^{0.5}$, where $n$ & represents the
\end{tabular}

number of binodal data. $w_{1}^{\text {exp }}$ is the experimental mass fraction of hydrophilic alcohols listed in Table 1 , and $w_{1}^{\text {cal }}$ is the corresponding data calculated using Eq. (3).

imental binodal along with the corresponding correlation coefficients $\left(R^{2}\right)$ and standard deviations $(s d)$ are given in Table 3 . The effective excluded volume represents the smallest spacing of an individual alcohol that will accept another individual salt molecule ${ }^{17}$. The larger the EEV value, the higher the salting-out ability of salts. As shown in Table 3 , the EEV values of the systems containing the salt with divalent anions (sulfate) are significantly higher than of those with monovalent anions (nitrate). Therefore, at the same cation, the salts with higher-valence anion are more likely to form a twophase system because water molecules are hydrating them, thus the amount of water available for alcohol molecules is decreased. Therefore, the salting-out ability increases. From Table 3, the EEV value of alcohol $+\mathrm{Na}_{2} \mathrm{SO}_{4}$ system is larger than that of the alcohol $+\left(\mathrm{NH}_{4}\right)_{2} \mathrm{SO}_{4}$ and the alcohol $+\mathrm{NH}_{4} \mathrm{NO}_{3}$ system with the same alcohols, which indicates that the phase-forming strength and the salting-out ability of $\mathrm{Na}_{2} \mathrm{SO}_{4}$ is stronger than $\left(\mathrm{NH}_{4}\right)_{2} \mathrm{SO}_{4}$ and $\mathrm{NH}_{4} \mathrm{NO}_{3}$, which is certainly consistent with the observations in Fig. 1. It can be seen from Fig. 1 that the two-phase area of alcohols $+\mathrm{Na}_{2} \mathrm{SO}_{4}$ systems are larger than that of the alcohols $+\left(\mathrm{NH}_{4}\right)_{2} \mathrm{SO}_{4}$ and alcohols $+\mathrm{NH}_{4} \mathrm{NO}_{3}$ systems.

Also, a two-parameter equation (Eq. (4)) which is based on the binodal theory ${ }^{16}$ and has been successfully used for the LLE data of hydrophilic alcohol + salt and polymer + salt ATPSs, was used to predict the salting-out ability of the studied salts.

$$
\ln \frac{w_{1}^{t}}{w_{1}^{b}}=\beta+K_{s}\left(w_{2}^{b}-w_{2}^{t}\right)
$$

In the equation, $w$ is the mass fraction, subscripts "1" and "2" represent the alcohols and salts, superscripts " $\mathrm{t}$ " and " $\mathrm{b}$ " stand for the top and the bottom phases, respectively. $\beta$ is the constant relat-
Table 4 -Values of parameters of Eq. (4) for the studied AT$P S s$ at temperature $T=298.15 \mathrm{~K}$

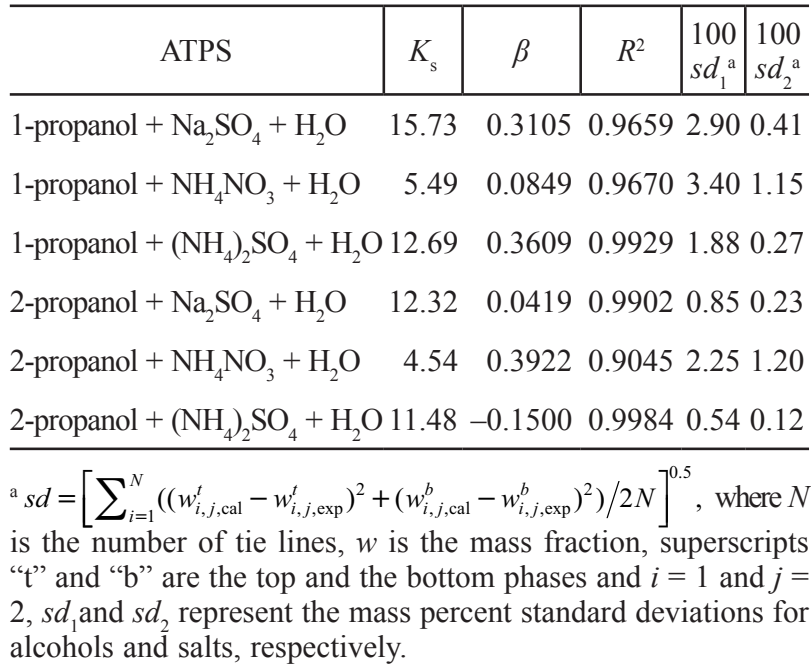

ed to the activity coefficient, and $K$ is the salting-out coefficient. Table 4 shows the fitting parameters along with the correlation coefficient $\left(R^{2}\right)$ and standard deviations $(s d)$ values in the studied systems. On the basis of the value of $R^{2}$ and $s d$, it can be concluded that Eq. (4) shows satisfactory accuracy in correlation of the tie-line data fitting for the investigated systems.

Recently, some authors have attempt to illustrate the salting-out effect on the basis of the value of $K_{\mathrm{s}}$ coefficient $^{1,18}$, in which the larger value of the $K_{\mathrm{s}}$ coefficient was attributed to the more salting-out ability of the salt. The results show that the value of salting-out coefficient for alcohols $+\mathrm{Na}_{2} \mathrm{SO}_{4}$ systems is nearly equivalent to the value in the systems composed of alcohols $+\left(\mathrm{NH}_{4}\right)_{2} \mathrm{SO}_{4}$ because both of these systems are composed of monovalent cation and divalent anion salts that have close salting-out ability. The salting-out coefficient values of systems containing alcohols $+\mathrm{NH}_{4} \mathrm{NO}_{3}$ are remarkably smaller than other ATPSs (Table 4). Overall, the changing trend of the EEV and the $K_{\mathrm{s}}$ coefficient values of these three salts in a same hydrophilic alcohol (in Tables 3-4) are in agreement with the visual comparison of the experimental data (Fig. 1).

\section{Effect of alcohols on phase separation}

The effect of the alcohol type on the binodal curves of the studied systems at $298.15 \mathrm{~K}$ is shown in Fig. 2. As it can be seen from Fig. 2, for the same salts in different component solvents, the phase separation ability of 1-propanol is higher than that of 2-propanol, and the area of the two-phase region has the following order: 1-propanol $>2$-propanol. There can be two reasons for this phenomenon. The dielectric constant of 1-propanol and 2-propanol is 20.6 and 19.4 at $298.15 \mathrm{~K}$, respectively. The dielectric constant, which is a usable tool to measure the 

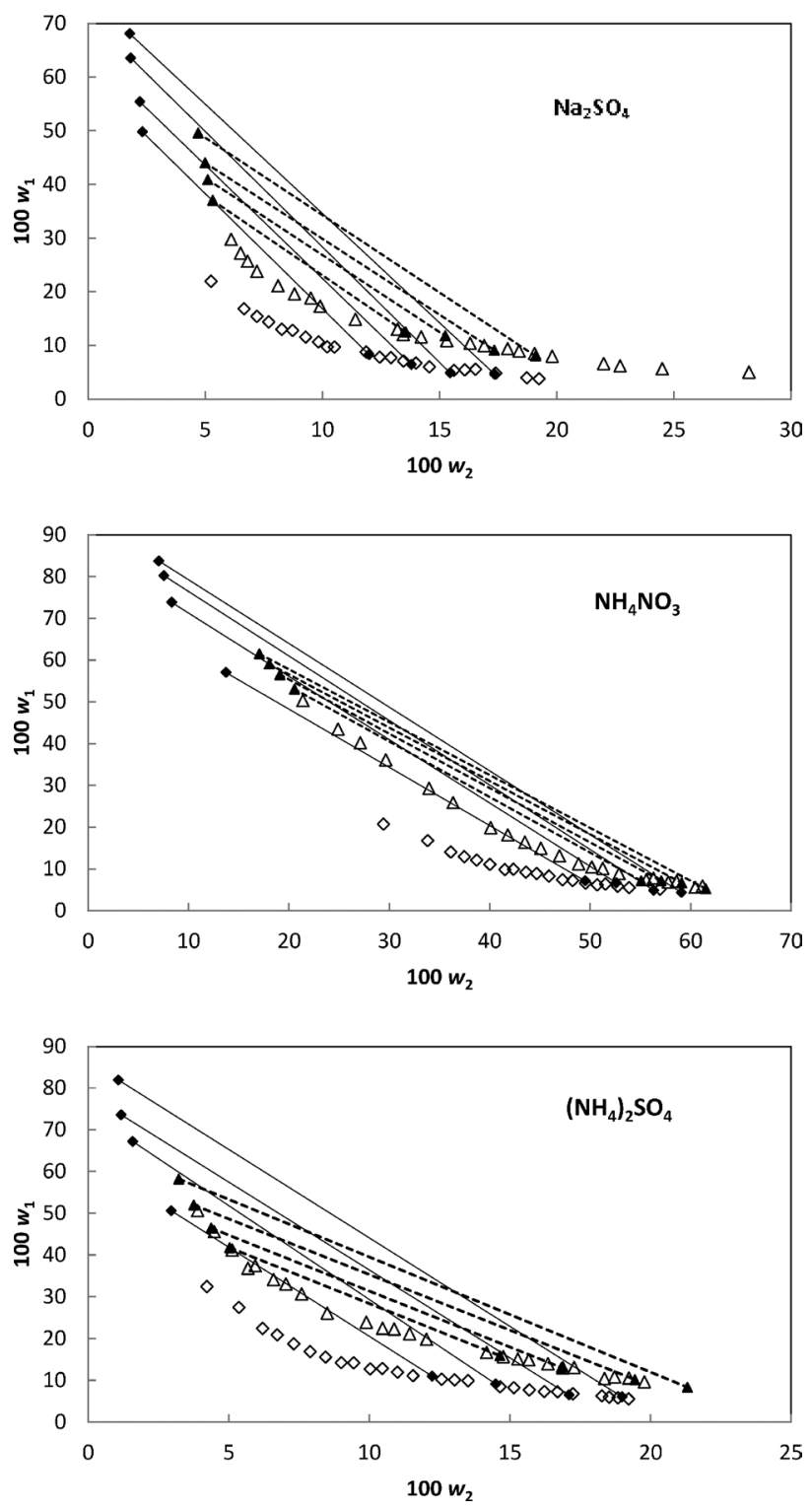

Fig. 2 - Effect of alcohol type on the binodal curves in mass fraction and tie-lines for the studied systems at $298.15 \mathrm{~K} ;(\diamond)$

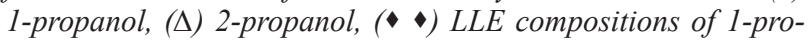
panol + salts $+\mathrm{H}_{2} \mathrm{O}$ systems and ( $\left.\mathbf{\Delta} \mathbf{\Delta}\right)$ LLE compositions of 2-propanol + salts $+\mathrm{H}_{2} \mathrm{O}$ systems. molecule's polarity, is higher for 1-propanol than 2-propanol, and the phase separation ability of the alcohols is related to the polarity of alcohol molecules. So the phase separation ability of 1-propanol is higher than that of 2-propanol.

On the other hand, since 1-propanol has a higher boiling point than 2-propanol (370.35 K and $355.45 \mathrm{~K}$, respectively), the boiling point may be considered an efficient criterion to represent the self-interaction forces between the alcohol molecules, as pointed out by Wang et al. ${ }^{19}$ Therefore, self-interaction forces between the molecules of the alcohol with the higher boiling point are stronger, so this alcohol can be easily excluded from the rest of the solution as a separated phase.

Also, in Table 3, it is shown that the value of $V^{*}{ }_{213}$ of the same salt in a solution increases from 2-propanol to 1-propanol. This could indicate that 1-propanol is easier to exclude from the aqueous (salt-rich) phase to the organic (alcohol-rich) phase. In other words, the phase-separation ability of alcohol increases with the increase in EEV. Thus, the phase-separation ability of the investigated alcohols is in the order 1-propanol $>$ 2-propanol, which is also proved by the area of the biphasic region shown in Fig. 2.

\section{Correlations}

\section{Correlation of binodal data}

The binodal data of the investigated systems were correlated using a four-parameter equation (Eq. 5), which has been successfully used by Han et al ${ }^{7}$ :

$$
w_{1}=\exp \left(a+b w_{2}^{0.5}+c w_{2}+d w_{2}^{2}\right)
$$

where $w_{1}, w_{2}$ represent the mass fraction of hydrophilic alcohol (1) and salt (2) respectively, and $a, b$, $c$, and $d$ are fitting parameters. The fitting parameters, correlation coefficients $\left(R^{2}\right)$, and standard deviations $(s d)$ are listed in Table 5. According to the obtained $R^{2}$ and standard deviations, it can be concluded that, Eq. (5) can successfully correlate the binodal curves of the investigated systems.

Table 5 -Values of parameters of Eq. (5) for the studied ATPSs at temperature $T=298.15 \mathrm{~K}$

\begin{tabular}{lrrrr|r|r}
\hline \multicolumn{1}{c}{ ATPS } & $a$ & $b$ & $c$ & $d$ & $R^{2}$ & $100 s d^{\mathrm{a}}$ \\
\hline 1-propanol $+\mathrm{Na}_{2} \mathrm{SO}_{4}+\mathrm{H}_{2} \mathrm{O}$ & 1.793 & -20.360 & 27.910 & -40.160 & 0.9976 & 0.22 \\
1-propanol $+\mathrm{NH}_{4} \mathrm{NO}_{3}+\mathrm{H}_{2} \mathrm{O}$ & -14.050 & 62.220 & -82.250 & 33.780 & 0.9973 & 0.21 \\
1-propanol $+\left(\mathrm{NH}_{4}\right)_{2} \mathrm{SO}_{4}+\mathrm{H}_{2} \mathrm{O}$ & 1.338 & -14.680 & 14.030 & -11.920 & 0.9958 & 0.41 \\
2-propanol $+\mathrm{Na}_{2} \mathrm{SO}_{4}+\mathrm{H}_{2} \mathrm{O}$ & 2.601 & -23.000 & 32.320 & -32.820 & 0.9979 & 0.33 \\
2-propanol $+\mathrm{NH}_{4} \mathrm{NO}_{3}+\mathrm{H}_{2} \mathrm{O}$ & -4.220 & 19.140 & -26.300 & 6.587 & 0.9991 & 0.40 \\
2-propanol $+\left(\mathrm{NH}_{4}\right)_{2} \mathrm{SO}_{4}+\mathrm{H}_{2} \mathrm{O}$ & 1.592 & -16.160 & 25.240 & -43.990 & 0.9981 & 0.52 \\
\hline
\end{tabular}

a $s d=\left(\sum_{i=1}^{n}\left(\mathrm{w}_{1}^{\text {cal }}-w_{1}^{\text {exp }}\right)^{2} / n\right)^{0.5}$, where $n$ represents the number of binodal data. $w_{1}^{\text {exp }}$ is the experimental mass fraction of hydrophilic alcohols listed in Table 1, and $w_{1}^{\text {cal }}$ is the corresponding data calculated using Eq. (5). 


\section{Correlation of tie-line data}

The reliability of the measured tie-line compositions was ascertained by the correlation equations given by Othmer-Tobias ${ }^{20}$ (Eq. (6)) and Bancroft ${ }^{21}$ (Eq. (7)). These equations have been widely used in the correlation of tie-line compositions of LLE systems ${ }^{11}$ as well as the hydrophilic alcohol-salt ATPS $^{1,7}$ :

$$
\begin{aligned}
\left(\frac{1-w_{1}^{t}}{w_{1}^{t}}\right) & =k_{1}\left(\frac{1-w_{2}^{b}}{w_{2}^{b}}\right)^{n} \\
\left(\frac{w_{3}^{b}}{w_{2}^{b}}\right) & =k_{2}\left(\frac{w_{3}^{t}}{w_{1}^{t}}\right)^{r}
\end{aligned}
$$

where $w_{1}{ }^{\mathrm{t}}, w_{3}{ }^{\mathrm{t}}$ represent the equilibrium compositions (in mass fraction) of the hydrophilic alcohol (1) and $\mathrm{H}_{2} \mathrm{O}(3)$ in the top phase, and $w_{2}{ }^{\mathrm{b}}, w_{3}{ }^{\mathrm{b}}$ represent equilibrium compositions (in mass fraction) of the salt (2) and $\mathrm{H}_{2} \mathrm{O}(3)$ in the bottom phase, respectively. $k_{1}, k_{2}$, $n$ and $r$ are fitting parameters. The linear relationship between $\ln \left(\left(1-w_{1}^{\mathrm{t}}\right) / w_{1}^{\mathrm{t}}\right)$ against $\ln \left(\left(1-w_{2}^{\mathrm{b}}\right) / w_{2}^{\mathrm{b}}\right)$, and $\ln \left(w_{3}^{\mathrm{b}} / w_{2}{ }^{\mathrm{b}}\right)$ against $\ln \left(w_{3}{ }^{\mathrm{t}} / w_{1}{ }^{\mathrm{t}}\right)$ are feasible in order to calculate the parameters $k_{1}, k_{2}, n, r$, and the corresponding correlation coefficient $\left(R^{2}\right)$ as well as standard deviation $(s d)$, and the results are given in Table 6 . According to the value of $R^{2}$ and $s d$, it can be concluded that Othmer-Tobias and Bancroft equations can be satisfactorily applied to the correlation of tieline data of the investigated systems, and the results show that the calculated values and experimental data are in good agreement.

\section{Conclusions}

Phase diagram data for 2-propanol/1-propanol + three different salts of $\mathrm{Na}_{2} \mathrm{SO}_{4} /\left(\mathrm{NH}_{4}\right)_{2} \mathrm{SO}_{4} /$ $\mathrm{NH}_{4} \mathrm{NO}_{3}+$ water systems were experimentally determined at $298.15 \mathrm{~K}$. The salting-out and the phase-forming ability of the mentioned ATPSs have been studied based on the effective excluded volume (EEV), the salting-out coefficient $\left(K_{\mathrm{s}}\right)$, the size and the Gibbs free energy of hydration of the ions. The salting-out ability of the investigated salts follows the order $\mathrm{Na}_{2} \mathrm{SO}_{4}>\left(\mathrm{NH}_{4}\right)_{2} \mathrm{SO}_{4}>\mathrm{NH}_{4} \mathrm{NO}_{3}$. Also, the phase-forming ability of hydrophilic alcohols is in the order: 1-propanol $>2$-propanol. The results show that the two parameters $K_{\mathrm{s}}$ and EEV can be used to evaluate the salting-out ability of other phase-forming salts, and will be very useful for designing an ATPS.

\section{References}

1. Guo, W., Ma, J., Wang, Y., Han, J., Li, Y., Song, S., Liquidliquid equilibrium of aqueous two-phase systems composed of hydrophilic alcohols (ethanol/2-propanol/1-propanol) and $\mathrm{MgSO}_{4} / \mathrm{ZnSO}_{4}$ at (303.15 and 313.15$) \mathrm{K}$ and correlation, Thermochim. Acta 546 (2012) 8. doi: http://dx.doi.org/10.1016/j.tca.2012.07.022

2. Khayati, G., Anvari, M., Aqueous two-phase systems composed of different molecular weight of polyethylene glycol and diammonium phosphate for extraction of Bovine Serum Albumin, Ital. J. Food Sci. 24 (2012) 279.

3. Khayati, G., Alizadeh, S., Extraction of lipase from Rhodotorula glutinis fermentation culture by aqueous twophase partitioning, Fluid Phase Equilib. 353 (2013) 132. doi: http://dx.doi.org/10.1016/j.fluid.2013.05.037

4. Khayati, G., Anvari, M., Shahidi, N., Partitioning of $\beta$-galactosidase in aqueous two-phase systems containing polyethylene eglycol and phosphate salts, Fluid Phase Equilib. 385 (2015) 147. doi: http://dx.doi.org/10.1016/j.fluid.2014.11.003

5. Khayati, G., Optimization of propionic acid extraction by aqueous two-phase system using response surface methodology, Chem. Eng. Comm. 200 (2013) 667. doi: http://dx.doi.org/10.1080/00986445.2012.721032

6. Khayati, G., Talesh, S. A., Yazdanshenas, M., Partitioning of propionic acid in polyethylene glycol/different salts of sulfate aqueous two-phase systems, Sep. Sci. Technol. 49 (2014) 2741.

doi: http://dx.doi.org/10.1080/01496395.2014.941490

Table 6 -Values of parameters of Eqs. 6 and 7 for the studied ATPSs at temperature T=298.15 K

\begin{tabular}{l|c|c|c|c|c|c|c|c}
\hline \multirow{2}{*}{ ATPS } & \multicolumn{3}{c|}{ Othmer-Tobias equation } & \multicolumn{4}{c}{ Bancroft equation } \\
\cline { 2 - 9 } & $k_{1}$ & $n$ & $R^{2}$ & $100 s d$ & $k_{2}$ & $r$ & $R^{2}$ & $100 s d^{\text {a }}$ \\
\hline 1-propanol $+\mathrm{Na}_{2} \mathrm{SO}_{4}+\mathrm{H}_{2} \mathrm{O}$ & 0.0265 & 1.8333 & 0.9798 & 1.01 & 6.7033 & 0.4759 & 0.9789 & 2.45 \\
1-propanol $+\mathrm{NH}_{4} \mathrm{NO}_{3}+\mathrm{H}_{2} \mathrm{O}$ & 0.6086 & 3.3780 & 0.9335 & 2.73 & 1.0348 & 0.2221 & 0.9755 & 6.47 \\
1-propanol $+\left(\mathrm{NH}_{4}\right)_{2} \mathrm{SO}_{4}+\mathrm{H}_{2} \mathrm{O}$ & 0.0043 & 2.7207 & 0.9790 & 1.66 & 6.5156 & 0.3206 & 0.9838 & 4.7 \\
2-propanol $+\mathrm{Na}_{2} \mathrm{SO}_{4}+\mathrm{H}_{2} \mathrm{O}$ & 0.1846 & 1.2037 & 0.9741 & 0.75 & 3.9622 & 0.6867 & 0.9767 & 1.26 \\
2-propanol $+\mathrm{NH}_{4} \mathrm{NO}_{3}+\mathrm{H}_{2} \mathrm{O}$ & 1.1268 & 1.2864 & 0.9830 & 0.41 & 1.1042 & 0.6771 & 0.9992 & 0.18 \\
2-propanol $+\left(\mathrm{NH}_{4}\right)_{2} \mathrm{SO}_{4}+\mathrm{H}_{2} \mathrm{O}$ & 0.1174 & 1.4174 & 0.9803 & 0.85 & 4.0734 & 0.5576 & 0.9800 & 1.69 \\
\hline
\end{tabular}

a $s d=\left(\sum_{i=1}^{n}\left(w_{1}^{c a l}-w_{1}^{e x p}\right)^{2} / n\right)^{0.5}$, where $n$ represents the number of tie-lines. $w_{1}{ }^{\text {exp }}$ is the experimental mass fraction of hydrophilic alcohols in the top phase mentioned in Table 2, and $w_{1}{ }^{\text {cal }}$ is the corresponding data calculated using Eqs. (6-7). $s d_{1}$ and $s d_{2}$ show the standard deviations in Eq. 6 and Eq. 7, respectively. 
7. Han, J., Wu, Y., Xiang, Y., Wang, Y., Ma, J., Hu, Y., Liquidliquid equilibria of hydrophilic alcohol + sodium hydroxide + water systems: Experimental and correlation, Thermochim. Acta 566 (2013) 261. doi: http://dx.doi.org/10.1016/j.tca.2013.06.008

8. Wu, X. Y., Liang, L. H., Zou, Y., Zhao, T., Zhao, J. L., Yang, $Q$., Aqueous two-phase extraction, identification and antioxidant activity of anthocyanins from mulberry (Morus atropurpurea Roxb.). Food Chem. 2011, 129, 443. doi: http://dx.doi.org/10.1016/j.foodchem.2011.04.097

9. Wang, Y., Han, J., Xu, X., Hu, S., Yan, Y., Partition behavior and partition mechanism of antibiotics in ethanol/2-propanol-ammonium sulfate aqueous two-phase systems, Sep. Purif. Technol. 75 (2010) 352 doi: http://dx.doi.org/10.1016/j.seppur.2010.09.004

10. Wang, Y., Wang, J., Han, J., Hu, S., Yan, Y., Liquid-liquid equilibrium of novel aqueous two-phase systems and evaluation of salting-out abilities of salts, Cent. Eur. J. Chem. 8 (2010) 886.

doi: http://dx.doi.org/10.2478/s11532-010-0053-8

11. Khayati, G., Pahlavanzadeh, H., Vasheghani-Farahani, E., Ghaemi, N., (Liquid + liquid) phase equilibria for (water + 2,3-butanediol + oleyl alcohol) at $T=(300.2,307.2$, and 314.2) K, J. Chem. Thermodyn. 41 (2009) 150. doi: http://dx.doi.org/10.1016/j.jct.2008.10.004

12. Feng, Z., Li, J. Q., Sun, X., Sun, L., Chen, J., Liquid-liquid equilibria of aqueous systems containing alcohol and ammonium sulfate, Fluid Phase Equilib. 317 (2012) 1. doi: http://dx.doi.org/10.1016/j.fluid.2011.12.023

13. Pirahmadi, F., Dehghani, M. R., Behzadi, B., Seyedi, S. M., Rabiee, $H$., Experimental and theoretical study on liquidliquid equilibrium of 1-butanol + water $+\mathrm{NaNO}_{3}$ at 25 and $35{ }^{\circ} \mathrm{C}$, Fluid Phase Equilib. 299 (2010) 122. doi: http://dx.doi.org/10.1016/j.fluid.2010.09.013
14. Chen, J., Zhong, Y., Han, J., Su, M., Shi, X., Liquid-liquid equilibria for water +1 - propanol (or 1-butanol) + potassium chloride +ammonium chloride quaternary systems at 298.15 K, Fluid Phase Equilib. 397 (2015) 50. doi: http://dx.doi.org/10.1016/j.fluid.2015.03.050

15. Marcus, $Y$., Thermodynamics of solvation of ions. Part 5. Gibbs free energy of hydration at $298.15 \mathrm{~K}$, J. Chem. Soc. Faraday Trans. 87 (1991) 2995. doi: http://dx.doi.org/10.1039/ft9918702995

16. Guan, Y., Lilley, T. H., Treffry, T. E., A new excluded volume theory and its application to the coexistence curves of aqueous polymer two-phase systems, Macromolecules 26 (1993) 3971. doi: http://dx.doi.org/10.1021/ma00067a037

17. Wang, Y., Hu, S., Yan, Y., Guan, W., Liquid-liquid equilibrium of potassium/sodium carbonate+2-propanol/ethanol+water aqueous two-phase systems and correlation at $298.15 \mathrm{~K}$, CALPHAD 33 (2009) 726.

doi: http://dx.doi.org/10.1016/j.calphad.2009.09.006

18. Lu, Y., Hao, T., Hu, S., Han, J., Tan, Z., Yan, Y., Measurement and correlation of phase diagram data for acetone and sulfate aqueous two-phase systems at different temperatures, Thermochim. Acta 568 (2013) 209. doi: http://dx.doi.org/10.1016/j.tca.2013.07.002

19. Wang, Y., Yan, Y. S., Hu, S. P., Han, J., Xu, X. H., Phase diagrams of ammonium sulfate + ethanol/1-propanol/2-propanol + water aqueous two-phase systems at $298.15 \mathrm{~K}$ and correlation, J. Chem. Eng. Data 55 (2010) 876. doi: http://dx.doi.org/10.1021/je900504e

20. Othmer, D. F., Tobias, P. E., Tie-line correlation, Ind. Eng. Chem. 34 (1942) 693. doi: http://dx.doi.org/10.1021/ie50390a600

21. González-Tello, P. G., Camacho, F., Blazquez, G., Alarcón, $F$. $J$., Phase diagrams of ammonium sulfate + ethanol/1-propanol/2-propanol + water aqueous two-phase systems at 298.15 K and correlation, J. Chem. Eng. Data 41 (1996) 1333. doi: http://dx.doi.org/10.1021/je960075b 